Revista Portuguesa de Ciência Política | Portuguese Journal of Political Science ISSN: 1647-4090 | ISSN-e: 2184-2078 | 2018, Número 9, Páginas 13-30

\title{
Hungria: O Estado de Direito em Crise?
}

\author{
Mariana Carmo Duarte* \\ * CIES-IUL, ISCTE - Instituto Universitário de Lisboa, Portugal
}

\section{Resumo}

Entre 2010 e 2011, o governo Fidesz-KDNP levou a cabo uma série de reformas legais, sociais e políticas, entre as quais a votação de uma nova constituição. Através da análise desta e das alterações à anterior constituição que a precederam, este artigo visa estudar a influência das recentes alterações ao quadro constitucional húngaro no Estado de Direito no país. Tendo por base a definição teórica de Estado de Direito, é possível argumentar que na Hungria têm sido minados princípios como a separação de poderes, a constitucionalidade das leis, a independência do poder judicial, bem como a dignidade da pessoa humana, a liberdade, a justiça e a segurança. Consequentemente, muitas têm sido as críticas ao governo de Orbán. Entre estas conta-se a da União Europeia, que vê na Hungria o primeiro Estado-membro a afastar-se dos valores democráticos da união.

Palavras-chave: Democracia; direitos fundamentais; Estado de Direito; Hungria; separação de poderes

\begin{abstract}
Between 2010 and 2011, the Fidesz-KDNP government carried out a number of legal, social and political reforms, including voting in a new constitution. Through analysis of this new constitution and amendments made to its predecessor, this article aims to understand the influence of the recent changes to the Hungarian constitutional framework with regard to the country's rule of law. Based on the theoretical definition of the rule of law, it can be argued that principles such as balance of power, constitutionality of laws, legality of administration, and independence of the judiciary and the media have been undermined in Hungary. Personal dignity, freedom, justice and security have also been undermined. As a result of these decisions, the number of voices critical of Orbán's government has grown. Among their numbers stands the European Union, which sees Hungary as the first Member State to deviate from the union's democratic values.
\end{abstract}

Keywords: balance of power; Democracy; fundamental rights; Hungary; Rule of Law 


\section{Introdução}

Na Hungria, em abril de 2010, o partido conservador e nacionalista, Fidesz ${ }^{[1]}$, em coligação com os cristãos democratas, $\mathrm{KDNP}^{[2]}$, obteve uma maioria absoluta nas eleições legislativas, que se traduziu numa maioria de dois terços de assentos parlamentares. Entre 2010 e 2011, garças a esta maioria qualificada e legitimado pela consulta popular, o governo de Viktor Orbán levou a cabo uma série de reformas legais, sociais e políticas, com o objetivo de reforçar e perpetuar o seu poder. Entre estas reformas contam-se a votação de uma nova constituição, denominada Lei Fundamental da Hungria, a alteração do sistema eleitoral, a restrição do poder de instituições independentes, como o Tribunal Constitucional, o controlo do Estado sobre os meios de comunicação e inúmeras restrições de iniciativas populares, liberdade de imprensa e liberdades civis (Bánkuti, Halmai \& Scheppele, 2015, pp. 37-45; Kovács \& Tóth, 2011; Lendvai, 2012, p. 222). Nas eleições de abril de 2014, a mesma coligação reiterou a sua posição dominante na cena política e parlamentar húngara.

Estas mudanças, embora tenham cumprido e respeitado os procedimentos legais, têm culminado num enfraquecimento preocupante das instituições democráticas, que muitos interpretaram como uma diminuição significativa do Estado de Direito (Hedling, 2014, p. 142). Nestes moldes, a Hungria aparece como um caso sui generis: se geralmente o Estado de Direito é minado pelo poder arbitrário das elites dirigentes, na Hungria o Estado de Direito foi enfraquecido através de normas e procedimentos legais. Devido à sua maioria de dois terços no parlamento unicameral húngaro, poucos foram os obstáculos enfrentados pelo partido de Orbán para concretizar a sua “revolução constitucional” (Bugaric, 2014, pp. 7-8). Partindo destes factos, este artigo visa analisar a influência da alteração do quadro constitucional húngaro no Estado de Direito neste país, respondendo à questão: em que medida é o Estado de Direito na Hungria afetado pelas recentes mudanças constitucionais? Para tal, são analisadas as alterações à anterior constituição, bem como a nova constituição húngara - Lei Fundamental -, ambas impulsionadas pela coligação governativa Fidesz-KDNP.

O presente artigo está estruturado em duas partes. Em primeiro lugar, é apresentado e discutido de forma teórica o conceito de Estado de Direito. Em segundo lugar, partindo desta definição conceptual, é analisada a desconstrução do Estado de Direito na Hungria. Assim, e acreditando que este conceito pode ser divido em duas características básicas, é analisada a influência das mudanças constitucionais, quer nos seus elementos formais (relacionados com a separação de poderes: ameaças aos poderes do Tribunal Constitucional e a independência do poder judicial, entre outros), quer nos seus elementos materiais (relacionados com os direitos fundamentais: criminalização dos sem-abrigo e ataques à liberdade religiosa e à liberdade de expressão, entre outros). São, ainda, enunciadas algumas das críticas feitas, quer por partidos da oposição, quer por forças internacionais, ao recente ordenamento constitucional húngaro. Complementarmente, é estudada a forma como a União Europeia

1. Aliança Cívica Húngara, Fidesz - Magyar Polgári Szövetség.

2. Partido Popular Democrata Cristão - Kereszténydemokrata Néppárt. 
(UE) tem lidado com este caso no seio da sua organização, através do Relatório Tavares e subsequente resolução do Parlamento Europeu (PE).

\section{O Estado de Direito - Uma Abordagem Conceptual}

\subsection{Estado de Direito, Estado de não-direito e "Soberania" da Lei}

A noção de Estado de Direito não é, hoje em dia, algo que esteja exclusivamente confinado ao léxico jurista. Pelo contrário, o seu uso tem-se massificado na linguagem quotidiana, política, jornalística e universitária (Novais, 1987, p. 9). Assim, se é o uso "indiscriminado" do termo que torna necessária uma definição clara e concisa que o balize e delimite, é, também, esse mesmo uso - a difusão do termo e a sua utilização em contextos variados - que leva a que a sua clarificação se torne uma tarefa árdua (Amaral, 2005, p. 139; Novais, 1987, pp. 9-11). Para uma maior compreensão do conceito de Estado de Direito, e acreditando que uma forma de definir um conceito é estabelecer e delimitar o seu contrário, é aqui avançada uma definição de Estado de não-direito ou Estado do arbítrio (Amaral, 2005, pp. 139-140). A definição conceptual deste Estado, e a sua oposição face ao Estado de Direito, é relevante por ajudar a explicar a dicotomia direito/arbítrio representada na seguinte interrogação: qual é o melhor governo, um baseado na "soberania" da lei ou outro baseado na "soberania" dos homens? (Bobbio, 1987, p. 138).

Por Estado de não-direito, entendemos um Estado em que "o poder político se proclama desvinculado de limites jurídicos e não reconhece aos indivíduos uma esfera de liberdade ante o poder protegida pelo direito" (Canotilho, 1999, p. 11). É um Estado em que o poder se exerce através da força e não através do direito, ou seja, em que as leis valem apenas por serem leis do poder, socorrendo-se da força para se fazerem obedecer. É um Estado em que há uma contradição evidente e intolerável entre as leis jurídicas do Estado e os princípios de justiça (igualdade, liberdade e dignidade da pessoa humana). É um Estado que identifica direito com força, deixando sem qualquer defesa jurídica eficaz os cidadãos, os povos e as minorias, ao fazer crer que são direito mesmo as leis mais arbitrárias, bárbaras e desumanas. É aquele em que o direito deriva da "razão do Estado", porém, esta é imposta por chefes/déspotas e apenas cobre a sua vontade e os seus privilégios. Neste sentido, o direito é tudo o que os "chefes"/"partido" decretarem como politicamente correto. É, ainda, aquele Estado que se pauta por uma acentuada injustiça e desigualdade na aplicação do direito, isto é, um Estado em que um ato idêntico é sancionado de forma diferente consoante as pessoas em causa, como, por exemplo, quando cometido por um adversário político e um apoiante do "partido" (Amaral, 2005, pp. 139-140; Canotilho, 1999, pp. 11-15).

A origens do Estado de Direito estão expressas na ideia, já defendida por Platão e Aristóteles, de que "é sempre preferível numa comunidade política a "soberania" da lei sobre os homens do que a "soberania" de homens sobre si mesmos" (Amaral, 2005 , p. 140). Para o primeiro, as melhores condições para a vida num Estado seriam atingidas quando os governantes fossem "escravos da lei", que ele considerava ser a expressão dos “ditames da razão". Para o segundo, era, igualmente, necessário um domínio das leis, "razão sem paixões", em oposição a um domínio dos homens 
(Novais, 1987, pp. 18-21). Assim sendo, podemos, sinteticamente, entender o Estado de Direito como um Estado cuja atividade é determinada e limitada pelo direito ou, segundo o aforismo, a Rule of Law and not of men. Aliada à componente de limitação jurídica, quer do Estado, quer dos titulares do poder, existe, ainda, a componente de respeito, garantia e promoção dos direitos e liberdades fundamentais, como característica de um Estado de Direito (Novais, 1987, p. 16). A ideia aqui subjacente, e contrária à do Estado de não-direito, é a de que as leis devem ser gerais e abstratas, ou seja, devem ser válidas e aplicadas à generalidade dos casos, não havendo uma sanção diferente para diferentes pessoas. As leis devem, ainda, evitar o arbítrio, isto é, devem evitar o "capricho" dos chefes que queiram ser obedecidos (Amaral, 2005, pp. 140-141; Canotilho, 1999, p. 11).

Apresentados os traços básicos do conceito de Estado de Direito, depreendem-se os elementos, quer formais, quer materiais, que o constituem. Dos elementos formais fazem parte, principalmente, a separação de poderes, a constitucionalidade das leis, a legalidade da administração e a independência do poder judicial. De entre os elementos materiais contam-se, primordialmente, a dignidade da pessoa humana, a liberdade, a justiça e a segurança (Amaral, 2005). Depois desta explicação, e usando as palavras de Jorge Reis Novais, apresentamos uma breve definição do conceito em estudo: "Estado de Direito será, então, o Estado vinculado e limitado juridicamente em ordem à proteção, garantia e realização efetiva dos direitos fundamentais, que surgem como indisponíveis perante os detentores do poder e do próprio Estado" (Novais, 1987, p. 17).

\subsection{Evolução Histórica do Estado de Direito}

\subsubsection{O Estado Liberal de Direito}

A ideia de um Estado "domesticado" pelo direito aparece, historicamente, ligada à luta da burguesia contra o Estado de Polícia e é moldada, sobretudo, pelas instituições liberais resultantes das experiências liberais, vitoriosas nos Estados Unidos da América e em França. Porém, deve ainda ser dada importância ao papel da Inglaterra onde a "experiência liberal" se começou a viver no século XVIII (Miranda, 2011, p. 91; Novais, 1987, p. 37). Resultado das diversas experiências vividas nos vários países e com o objetivo de expressar a mesma ideia, encontramos diversas qualificações que exprimem a diversidade de contribuições teóricas desenvolvidas acerca do tema (Miranda, 2011, p. 92). Em Inglaterra, surgiu a ideia de Rule of Law. Dos Estados Unidos, chegou-nos a exigência do Estado Constitucional. De França emergiu a exigência do État Légal, Primauté du Droit ou Règne de la Loi. Na Alemanha, construiu-se o princípio do Rechtsstaat (Canotilho, 1999, pp. 24-27; Novais, 1987, pp. 37-51). Embora lexicalmente distintos, estes são termos semanticamente semelhantes: "Em vez da tradição, o contrato social; em vez da soberania do príncipe, a soberania nacional e a lei como expressão da vontade geral; [...] em vez da razão do Estado, o Estado como executor de normas jurídicas; em vez de súbditos, cidadãos e atribuição a todos os homens, apenas por serem homens, de direitos consagrados nas leis" (Miranda, 2011, p. 93). 
No que diz respeito à fundamentação teórica do Estado Liberal de Direito, é preciso realçar três nomes: Adam Smith, Immanuel Kant e Alexander von Humboldt. Adam Smith fixou a separação entre Estado e Economia. Para este, e baseando-se num "naturalismo otimista", tem de haver uma distinção entre política e economia, sendo as únicas funções do Estado as de garantir segurança e a propriedade dos cidadãos e estando a vida económica remetida para uma dinâmica de autorregulação dos mercados (Novais, 1987, pp. 52-57). Immanuel Kant estabeleceu a separação entre Estado e Moralidade. Para este, a moral corresponde à componente interna, isto é, à ação do Homem, aquilo que o leva a agir, enquanto que o Direito corresponde à componente externa, ou seja, ao evitar do arbítrio, para que cada um consiga coexistir com a moralidade dos outros. Na sua lógica, a moralidade e todos os problemas que lhe são adjacentes não podem ser resolvidos pelo Estado, mas sim pela consciência autónoma de cada indivíduo (Novais, 1987, pp. 58-62). Alexander von Humboldt determinou a separação entre Estado e Sociedade. Das duas dicotomias anteriores, surgiu esta, pois segundo este teórico a sociedade civil é o lugar onde coexistem as esferas morais e económicas dos indivíduos, sendo função do Estado a de garantir a paz social e a coexistência pacífica que permita o livre desenvolvimento dessa mesma sociedade de acordo com as suas próprias regras (Novais, 1987, pp. 63-67).

Como temos vindo a argumentar, só haverá Estado de Direito quando a proteção de direitos e liberdades fundamentais dos cidadãos for garantida pelo Estado, bem como quando estiver assegurada a separação dos poderes. O enfoque Liberal do Estado de Direito não deixou de prosseguir este fim, tal como proclama do artigo $16 .^{\circ}$ da Declaração de Direitos do Homem e do Cidadão de 1789: "Qualquer sociedade em que não esteja assegurada a garantia dos direitos, nem estabelecida a separação dos poderes não tem Constituição" (Miranda, 2011, p. 94). Contudo, o contexto histórico ajudou a que o Estado de Direito se moldasse aos interesses da burguesia ascendente, para quem o Estado de Direito é, mais do que um conceito filosófico, um "conceito de luta política" (Novais, 1987, p. 37). Assim sendo, deviam ser respeitados os valores da iniciativa privada, da segurança da propriedade, da livre fruição do sistema capitalista e da limitação do papel do Estado, ficando o Estado Liberal de Direito também a ser conhecido como Estado burguês (Miranda, 2011, p. 96).

Se houve um predomínio da Sociedade face ao Estado, também houve uma vitória do Direito face ao arbítrio. Foi estabelecido um conjunto de órgãos, cujas competências foram pré-estabelecidas constitucionalmente, e que consagrava a supremacia do poder legislativo e a subordinação do poder executivo. Assim, a divisão dos poderes conferia previsibilidade à ação do Estado e, aliada à institucionalização da justiça administrativa, era um garante das liberdades e direitos fundamentais (Novais, 1987, pp. 67-70). Adotando a definição de Jorge Miranda, "O Estado constitucional, representativo ou de direito aparece como Estado liberal, assente na ideia de liberdade e, em nome dela, empenhado em limitar o poder político tanto internamente, pela sua divisão, como externamente, pela redução ao mínimo das suas funções perante a sociedade" (Miranda, 2011, p. 96). 


\subsubsection{O Estado Social de Direito}

O século $\mathrm{xx}$ foi um século de mudanças culturais e sociais, foi o século das duas grandes guerras mundiais, o século dos avanços tecnológicos, o século da proteção dos direitos humanos e o século das crises económicas. Estes e outros acontecimentos, que marcaram o século passado, ajudaram a que fossem alterados alguns paradigmas políticos e sociais e a que o Estado de Direito perdesse o adjetivo Liberal para adquirir o Social (Miranda, 2011, pp. 99-100). A compreensão do Estado Social de Direito pressupõe os entendimentos dos elementos de continuidade e de rutura face ao anterior estádio do Estado de Direito. Por um lado, mantêm-se a limitação jurídica do Estado e a juridicização das suas relações com os cidadãos, implicando isto a manutenção da divisão de poderes, do princípio da legalidade da administração e da tutela jurisdicional dos direitos individuais. Por outro lado, no século xx, o Estado de Direito, apelidado de Social, passa a ter como função a criação de condições que garantam igual oportunidade de realização da dignidade e da personalidade humanas. O Estado sofre uma transformação num sentido mais democrático, intervencionista, social, em oposição ao laissez faire liberal (Novais, 1987, pp. 212-220). Assim, do que se trata é de articular direitos, liberdades e garantias — proteger a autonomia das pessoas - com direitos sociais - refazer as condições materiais e culturais em que vivem as pessoas, através de um equilíbrio das clivagens sociais, estímulos regulativos do Estado a favor da justiça social, estabelecimento de regras jurídicas em prol do emprego e dos direitos dos trabalhadores, entre outras medidas (Miranda, 2011, pp. 105-106).

Contra a ideia de Estado Social de Direito surge a ideia, defendida por liberais e, hoje em dia, por neoliberais, de que os direitos sociais se realizam melhor sem o Estado do que através deste. Para estas correntes, a experiência demonstrou que é através da autorregulação do mercado, ao garantir a efetivação dos próprios direitos económicos, sociais e culturais, que é garantida a justiça distributiva, sem ser posta em perigo a liberdade. Assim, não é ao Estado, e muito menos a um Estado de Direito, que cabe impor e realizar fins sociais. O que estes pretendem é deslegitimar qualquer Estado que reivindique para si a realização da justiça social, da igualdade, da solidariedade e dos direitos económicos, culturais e sociais. A crítica formulada por estas correntes a pretexto do Estado de Direito retoma a crítica aos regimes totalitários que marcaram o século xx. Para os apoiantes destas ideias, o Estado de bem- estar ou no Estado-providência é tido como uma manifestação clara da "ambição" totalitária, como uma forma deste Estado alargar os seus ímpetos intervencionistas, ameaçando as liberdades individuais (Canotilho, 1999, pp. 36-39).

Porém, uma coisa é um "Estado social ou Estado socialista" de não-direito e outra, bastante diferente, é um Estado Social de Direito. "Este tipo de Estado é a tentativa qualitativa para tornar compatível o desenvolvimento económico com uma ordem social justa na qual se definam antecipadamente as dimensões constitucionais e essenciais dessa ordem, em vez de se acreditar nos acertos resultantes da mera concorrência de forças económicas" (Canotilho, 1999, p. 39). 


\subsubsection{O Estado de Direito Democrático}

Ao Estado de Direito, tal como o definimos e abordámos, faltava um elemento fundamental: a legitimação democrática do poder. Assim, o elemento democrático, quando introduzido, não o foi apenas para conter o poder - to check the power -, mas foi, principalmente, reclamado pela necessidade de legitimação do mesmo poder, de constituir uma ordem legitimada pelo povo, respondendo à pergunta: "de onde vem o poder?”. Ora, só o princípio da soberania popular, segundo o qual todo o poder advém do povo, assegura e garante o direito à igual participação na formação democrática da vontade popular. Neste sentido, o princípio da soberania popular serve de elo de ligação entre o Estado de Direito - rule of law - e o Estado democrático - rule of men - , possibilitando a compreensão da moderna fórmula Estado de Direito democrático: o governo dos Homens como um governo sob e através de leis. Tal implica que um Estado de Direito é democrático e que só o é sendo democrático, tal como um Estado democrático é de direito e só o é se for de direito (Canotilho, 1999, pp. 27-37).

É com o advento, aprofundamento e generalização das regras da democracia política que o Estado de Direito consegue legitimar o seu novo princípio Social. Com a extensão exigida pela atual definição de dignidade da pessoa humana, os direitos fundamentais só obtêm legitimação e reconhecimento num regime democrático. Isto porque é com o reconhecimento de direitos políticos - só possível num regime democrático - que é conferida legitimidade à esfera dos direitos e autonomia individuais, até porque a realização destes direitos e autonomia num regime autoritário tem um alcance muito diferente que num regime democrático. Também a tradicional divisão dos poderes é legitimada pelo princípio democrático. A democracia política, nesta lógica, assume-se como uma dimensão essencial ao Estado Social de Direito, sendo este indissociável daquela (Novais, 1987, pp. 221-223). "Assim, se o Estado de Direito tem sido no século $\mathrm{xx}$, por exigência da verificada assunção do novo princípio de sociabilidade, Estado de Direito Social, [este] é, por inerência da natureza dos valores que prossegue, Estado Democrático de Direito" (Novais, 1987, p. 223).

\section{O Estado de Direito - O Caso da Hungria}

Desde a queda do Muro de Berlim e dos regimes comunistas, muitos países da Europa Central e do Leste têm gerido, com êxito, o seu "retorno à Europa". Para muitos observadores, este retorno tem sinalizado a vitória da democracia e do Estado de Direito face ao legado autoritário deixado nesta região do globo. De entre estes países que em 1989 iniciaram o processo de transição para a democracia, a Hungria era tida como um dos mais promissores no que diz respeito à consolidação e manutenção de um Estado de Direito (Lewis, Lomax \& Wightman, 1994, pp. 157-158; Muller, 2011, p. 5; Norwegian Helsinki Committee [NHC], 2012, p. 3). Todavia, desde 2010, que os governos de Viktor Orbán parecem estar a guiar o país para uma deriva autoritária e a enveredar por um retrocesso democrático (Dettke, 2014, p. 4). Recentemente, o "modelo" húngaro parece estar a ser exportado para outros países desta zona do mundo, nomeadamente para Polónia, onde a elite política está empenhada em desconstruir o Estado de Direito neste país. 
A deriva autoritária e nacionalista húngara deve ser analisada à luz da crise económica e financeira que atingiu o país no ano de 2008. Nesse ano, a estagnação da economia, motivada pela elevada dívida pública, traduziu-se num escalar das tensões e manifestações sociais. Em 2010, devido a uma série de escândalos de corrupção que envolveram o governo socialista incumbente - $\mathrm{MSZP}^{[3]}$-, bem como devido aos crescentes problemas económicos, mais de metade do eleitorado alterou o seu sentido de voto, dando uma maioria qualificada de dois terços de assentos parlamentares à coligação de direita nacionalista, Fidesz-KDNP (Beissinger \& Sasse, 2014, p. 359; Stegmaier \& Lewis-Beck, 2011, p. 463). A maioria qualificada do partido de Viktor Orbán foi reiterada nas eleições de abril de 2014. Também o partido de extrema-direita e ultranacionalista, Jobbik ${ }^{[4]}$, viu a sua percentagem de votos aumentar, quer em 2010, quer em 2014 (Nagy, Boro \& Vasali, 2013, p. 229; NHC, 2012, p. 3).

\subsection{As Alterações Constitucionais e Lei Fundamental}

\subsubsection{Elementos formais}

A Hungria foi o único país pós-comunista a não ter redigido uma Constituição inteiramente nova aquando da transição para a democracia. Assim, neste país, foi através de alterações à antiga Constituição, levadas a cabo entre 1989 e 1990, que foi criado o quadro legal que possibilitou o estabelecimento do novo regime democrático. Entre outras mudanças, foi instaurado um governo representativo, um sistema parlamentar, um poder judiciário independente e um Tribunal Constitucional, que revisse a constitucionalidade das leis (Kovács \& Tóth, 2011, p. 184; Muller, 2011, p. 5).

A maioria qualificada de dois terços, resultado das eleições de 2010, permitiu ao governo húngaro, nos anos de 2010 e 2011, começar uma série de profundas reformas constitucionais, que serviram de prelúdio para um nova Constituição (Kovács \& Tóth, 2011, p. 184; Muller, 2011, p. 5). Numa das primeiras emendas constitucionais, o governo de Viktor Orbán eliminou da antiga Constituição o artigo que exigia um mínimo de quatro quintos de votos no Parlamento para aprovar as regras para a elaboração de uma nova Constituição. O objetivo deste artigo, introduzido na Constituição em 1995, era proteger os interesses dos partidos minoritários, visto que um voto de quatro quintos tornava quase impossível uma mudança de Constituição sem consulta dos partidos da oposição. Uma vez que a regra de alteração de um artigo apenas requeria uma maioria de dois terços, o governo Fidesz usou a sua maioria qualificada para eliminar a regra dos quatro quintos para a elaboração de uma nova Constituição (Bugaric 2014, pp. 8-10, 2016).

$\mathrm{O}$ que se seguiu foi uma série de alterações constitucionais que mudaram as regras que regulavam o Tribunal Constitucional, o processo de referendo e a autoridade responsável pelo controlo dos meios de comunicação. No que respeita ao Tribunal Constitucional, foram alteradas as regras para a nomeação dos seus juízes de modo a que o Fidesz pudesse usar a sua maioria de dois terços para nomear seus pró-

3. Partido Socialista Húngaro - Magyar Szocialista Párt.

4. Movimento por uma melhor Hungria - Jobbik Magyarországért Mozgalom. 
prios candidatos. Este tribunal assistiu, à semelhança do que aconteceu nos Estados Unidos com o Court Packing Plan ${ }^{[5]}$ de Roosevelt, ao aumento do número dos seus juízes de oito para quinze, sendo os sete novos lugares preenchidos com candidatos do partido no governo. Este tribunal viu, ainda, restringidas as suas competências sobre questões fiscais (Bugaric, 2014, pp. 8-10; Sadecki, 2014, pp. 10-14; Scheppele, 2011). No que diz respeito ao processo de referendo, o governo Fidesz colocou sob o seu controlo político a Comissão Eleitoral, o que é importante dado que esta tem o poder de controlar as iniciativas de referendo. Relativamente aos meios de comunicação, o governo reorganizou a autoridade responsável por estes, completando-a com o Conselho de Comunicação Social, um “órgão independente" com cinco membros, responsável pelo controlo dos órgãos de comunicação social. O novo presidente da autoridade responsável pelos meios de comunicação é um antigo deputado do Fidesz. Os cinco lugares do Conselho de Comunicação Social foram preenchidos por cinco candidatos do mesmo partido (Bugaric, 2014, pp. 8-10; NHC, 2012, p. 3).

Sem mudar a lei, o governo Fidesz elegeu para novo presidente da Hungria, Pál Schmitt, uma figura forte do partido. A Constituição húngara dá importantes poderes de controlo ao presidente. Este pode exercer o poder de veto suspensivo, devolvendo leis ao Parlamento para a revisão, e pode iniciar uma revisão constitucional antes o Tribunal Constitucional. Com o "seu" presidente no poder, o governo não temia essas verificações adicionais sobre o seu poder executivo. Assim, estava criada uma abertura através da qual o governo Fidesz podia começar a desenhar uma nova Constituição (Bugaric, 2014, pp. 8-10). A 18 de abril de 2011, o Parlamento aprovou uma nova Constituição, sob o título de Lei Fundamental da Hungria ${ }^{[6]}$ (Kovács \& Tóth, 2011, p. 183). Uma semana depois, a 25 de Abril, no primeiro aniversário das eleições de 2010, a nova Lei foi promulgada pelo Presidente da República. Entrou em vigor a 1 de janeiro de 2012 (Jakab \& Sonnevend, 2013, p. 102).

A nova Constituição contém várias disposições que minam radicalmente os pressupostos básicos do sistema de separação de poderes. No que diz respeito ao Tribunal Constitucional, o acesso a este foi limitado: o antigo sistema de actio popularis, que permitia que qualquer pessoa levasse um caso a Tribunal foi substituído pelo modelo alemão de verfassungsbeschwerde ${ }^{[7]}$, limitando, assim, o acesso ao Tribunal apenas a indivíduos cujos direitos constitucionais tenham sido violados pela autoridade pública (Scheppele, 2011).

Em relação à reforma no poder judicial, com a redução da idade de reforma dos juízes dos 70 para os 62 anos, o governo Fidesz conseguiu remover um elevado número destes. A legislação relativa ao poder judicial estabeleceu um novo Conselho Nacional de Justiça, com o poder de substituir os juízes que se aposentam e nomear

5. O Court Packing Plan foi uma iniciativa legislativa, proposta pelo presidente americano Franklin D. Roosevelt, para adicionar mais juízes ao Tribunal Supremo dos Estados Unidos. O objetivo de Roosevelt era obter decisões favoráveis no que diz respeito à legislação do New Deal, que o Tribunal tinha considerado inconstitucional.

6. Magyarország Alaptörvénye.

7. Artigo $24 .^{\circ}(2) \mathrm{c}$ ). 
novos juízes. Para o cargo de presidente deste órgão foi nomeado um amigo próximo de Orbán. O presidente deste Conselho tem competência para transferir casos específicos de um tribunal para outro e, aquando de uma emenda constitucional, para escolher, em conjunto com o Ministério Público, que juiz vai julgar o caso. O Presidente é eleito para um mandato de nove anos ${ }^{[8]}$ (Bugaric, 2014, pp. 7-14; Lendvai, 2012, p. 222; Scheppele, 2011). A nova lei sobre o sistema judicial exige que o presidente do Supremo Tribunal (Kúria), que é também membro do Conselho Nacional de Justiça, tenha, pelo menos, cinco anos de experiência no sistema judicial húngaro. Neste sentido, o presidente à data da entrada em vigor da nova Constituição, András Baka, foi afastado do cargo, pois os seus 17 anos de experiência como juiz no Tribunal Europeu dos Direitos Humanos não cumprem os requisitos (Scheppele, 2011).

Outro exemplo do uso de ferramentas legais/constitucionais para minar o sistema de separação de poderes é a criação de vários novos organismos, como o Conselho de Orçamento ${ }^{[9]}$, o Serviço Nacional de Auditoria ${ }^{[10]}$ e a Procuradoria-Geral ${ }^{[11]}$, que são, atualmente, compostos por apoiantes do partido no governo. Estes órgãos têm mandatos longos (de 6 a 12 anos) e a eleição dos seus membros, ou de parte dos seus membros, requer uma maioria de dois terços no parlamento. Estes órgãos estão revestidos de fortes poderes de veto em decisões importantes do Parlamento e têm o poder de investigar o governo e atribuir um processo criminal específico a um tribunal de sua escolha (Scheppele, 2011). Dado este "entrincheirar" do Fidesz em todos os domínios do Estado, para qualquer governo futuro que não tenha uma maioria de dois terços no Parlamento será extremamente difícil, se não impossível, substituir os membros Fidesz, dos cargos de poder, por novos candidatos (Bugaric, 2014, pp. 7-14; Lendvai, 2012, p. 208).

\subsubsection{Elementos materiais}

No que diz respeito à garantia e proteção de direitos fundamentais, Viktor Orbán tem sido acusado de implementar muitas políticas inspiradas pelo partido de extrema-direita, Jobbik, e que colocam em causa a proteção destes mesmos direitos (Lendvai, 2012, pp. 179-194; Nagy, Boro \& Vasali 2013, pp. 244-249). Nas palavras de Jorge Reis Novais, "[...] só haverá Estado de Direito quando no cerne das preocupações do Estado e dos seus fins figurar a proteção e garantia dos direitos fundamentais [...]" (Novais, 1987, p. 16). No caso húngaro, foi o progressivo desmantelar do sistema de separação de poderes, com o enfraquecimento do poder judicial e o aumento das competências do poder executivo, que possibilitou o gradual ataque aos direitos fundamentais, também ele por via legal/constitucional, através de alterações à Lei Fundamental.

\footnotetext{
8. Artigo 25.० (6).

9. Artigo $44 .^{\circ}$

10. Artigo $43 .^{\circ}$

11. Artigo $29 .^{\circ}$
} 
As questões relativas à situação das populações cigana e judaica na Hungria não são novas, porém estas têm-se agudizado nos últimos anos (Lendvai, 2012, p. 179). Por exemplo, a minoria cigana tem sido "forçada" a realizar trabalho comunitário/ voluntário e permitir que as suas casas e as suas propriedades sejam inspecionadas para que possam receber prestações sociais. $\mathrm{O}$ violento e odioso discurso contra quer ciganos, quer Judeus, tem-se tornado uma rotina quase diária na Hungria. Há relatos de violência física contra ciganos e declarações antissemitas que exigem que todos os judeus que vivem na Hungria sejam registados e seja avaliado o seu potencial perigo para o país. Para além disto, e em jeito de concessão aos anti-ciganos e antissemitas, os direitos das organizações paramilitares têm sido aumentados. Vários intelectuais, ideologicamente perto do Fidesz, têm feito renascer várias obras antissemitas de escritores do período entre guerras (Bugaric, 2014, pp. 20-21).

A Lei Fundamental estabelece que é competência quer do governo, quer das administrações locais, fornecer a todas as pessoas uma habitação condigna e acesso aos serviços públicos, devendo estes esforçar-se para fornecer alojamento a todas as pessoas sem alojamento ${ }^{[12]}$. Porém, relativamente aos sem-abrigo, a Lei Fundamental estabelece que é competência das comunidades locais qualificar a residência permanente de pessoas em espaços públicos como não conforme à lei, por razões de segurança e saúde pública ${ }^{[13]}$. Assim sendo, não ter casa, e não ter outra opção para além de permanecer no espaço público, é crime. Importa lembrar que, na Hungria, estima-se que cerca de 30000 a 35000 pessoas, incluindo mulheres, crianças, idosos e pessoas com deficiência sejam sem-abrigo (Grabenwarter, Hoffmann-Riem, Suchocka, Tuori \& Velaers, 2013, pp. 15-16).

Outros artigos da Lei Fundamental são acusados de limitar as liberdades civis e, portanto, de porem em causa o Estado de Direito na Hungria. Estes incluem, por exemplo, a obrigação, por parte dos estudantes que receberam subsídios estatais, a terem que ficar e trabalhar na Hungria durante um determinado período de tempo depois de terminarem os seus estudos ${ }^{[14]}$. Caso não o façam, terão de pagar, ao Estado, o montante total da bolsa de estudo que receberam. Ainda em relação ao Ensino, segundo a Lei Fundamental, as instituições de ensino superior devem ter autonomia no que diz respeito aos conteúdos e metodologias de pesquisa e ensino, porém deve ser o governo a definir as regras, bem como a supervisionar a gestão financeira destas ${ }^{[15]}$. Assim, esta limitação da autonomia económica das universidades mina a garantia do livre pensamento, sendo uma forma indireta, do governo penetrar nas questões do conteúdo e metodologias do ensino (Grabenwarter et al., 2013, pp. 14-15).

Certas sociedades religiosas foram, também elas, afetadas pelo novo ordenamento constitucional. Cabe ao parlamento o direito exclusivo de decidir quais as organizações religiosas que são consideradas "igrejas" ${ }^{[16]}$, sendo estas aquelas que se

\footnotetext{
12. Artigo XXII (1) (2).

13. Artigo XXII (3).

14. Artigo XI (3).

15. Artigo X (3).

16. Artigo VII (4).
} 
propuserem a cooperar com o Estado, não pondo a Lei Fundamental em causa. Assim sendo, atualmente, apenas 14 igrejas têm mantido um estatuto reconhecido pelo Estado, estando o direito à liberdade de consciência e de religião a ser posto em causa (NHC, 2012, p. 9). No que diz respeito à definição de família, esta é tida como aquela fundada a partir do casamento entre um homem e uma mulher e/ou como uma relação entre pais e filhos ${ }^{[17]}$. Esta é uma definição bastante restrita que continua a dar preferência às famílias ditas tradicionais (ou seja, a família de casais heterossexuais), discriminando não só família de casais do mesmo sexo, mas também famílias em que não tenha havido casamento. Esta definição não engloba, ainda, casais que não têm ou não podem ter filhos, bem como netos que estão ao cuidado dos avós, etc. (Grabenwarter et al., 2013, p. 6).

\subsection{As Críticas e a Resposta da União Europeia ao Novo Ordenamento Consti- tucional Húngaro}

Os trabalhos de preparação da Lei Fundamental, bem como o seu conteúdo, foram duramente criticados, não só pelos partidos de oposição húngaros, mas também por meios de comunicação e forças políticas estrangeiras, entre elas a UE. Alegava-se que o novo ordenamento constitucional húngaro era antidemocrático, pouco transparente e que sinalizava o fim do Estado de Direito (Jakab \& Sonnevend, 2013, p. 102; Tartakoff, 2012, p. 360). A ideia destes era a de que o governo de Viktor Orbán tinha conseguido transformar aquilo que era um caso de sucesso, no que diz respeito à transição para a democracia, num regime semi-autoritário, baseado numa ordem constitucional antiliberal, que tinha enfraquecido as liberdades fundamentais e o sistema de separação de poderes e, assim, comprometido o Estado de Direito (Bugaric, 2014, pp. 7-8). Estas acusações foram veementemente negadas pelo governo húngaro que argumentava ter recebido um mandato popular para acabar, definitivamente, como o legado comunista e concluir a mudança de regime, começada em 1989. A nova Lei Fundamental era uma forma de o conseguir (NHC, 2012, p. 3). Também o processo de mudança constitucional húngaro foi posto em causa. Este foi visto como muito rápido, tendo em conta a profundidade e amplitude das mudanças. A falta de consulta do eleitorado e da oposição também foi apontada como um problema (Hedling, 2014, p. 143).

Enquanto, por um lado, vários autores concordam que a nova ordem constitucional mina os princípios basilares do Estado de Direito, alguns chegam a comparar a retórica de Viktor Orbán com a de Miklós Horthy ${ }^{[18]}$, dado que ambos manifestam um forte antissemitismo, anticomunismo e uma obsessão com o trauma de Tria-

17. Artigo L (1).

18. Miklós Horthy foi um almirante e estadista húngaro, que governou a Hungria durante período entre guerras entre, de março de 1920 a outubro de 1944. Fortemente nacionalista e conservador, durante o seu governo proibiu o partido comunista e adotou uma política externa agressiva de restabelecimento das fronteiras como definidas antes do Tratado de Trianon (Cartledge, 2011). 
non $^{[19]}$ (Rupnik, 2012, p. 134). Por outro lado, há um menor consenso sobre como a definir: se ela pode ou não ser chamada de antiliberal, se estamos ou não perante um novo autoritarismo ou se podemos ou não afirmar que estamos perante uma "democracia-guiada", ao estilo de Putin (Muller, 2011, p. 5).

No contexto europeu, a deriva autoritária húngara tem-se afigurado como um desafio para UE e para os seus princípios e valores. Conhecida por ser uma organização composta por países democráticos, que prima pelos valores do Estado de Direito, da democracia e do respeito pelos direitos fundamentais, a UE tem o caso húngaro como exemplo do primeiro Estado-Membro a pôr em causa o respeito por todas estas características, caminhando rumo a um regime antiliberal e antidemocrático (Bugaric, 2014, p. 1, 2016). Recentemente, e por efeito dominó, também a Polónia parece estar a ser encaminhada, pela mão de Beata Szydlo, para uma deriva autoritária, que coloca em questão os valores fundamentais da UE.

Em Julho de 2013, o PE criticou duramente as recentes mudanças constitucionais na Hungria, aprovando uma resolução com base num relatório da comissão das Liberdades Cívicas, Justiça e Assuntos Internos (LIBE), apelidado de Relatório Tavares $^{[20]}$ (Hedling, 2014, p. 141). Este relatório e a resolução que nele se baseou criticam duramente a situação dos direitos fundamentais na Hungria, recomendando a criação de um mecanismo independente que siga a situação nesse país. Este relatório prevê a criação de uma "Comissão de Copenhaga", isto é, uma comissão que reveja a continuação do cumprimento dos critérios de Copenhaga ${ }^{[21]}$ utilizados para admissão de qualquer Estado membro na UE. Esta comissão irá dar recomendações às instituições da UE, bem como aos seus Estados-Membros, sobre como responder e solucionar qualquer deterioração dos valores fundamentais da União (Bugaric, 2014, pp. 4-5, 2016; Tavares, 2012).

Esta resolução mostra como o governo húngaro tem negligenciado as suas obrigações de cumprir o Tratado da União Europeia (TUE), principalmente o $2 .^{\circ}$ artigo deste: "A União funda-se nos valores do respeito pela dignidade humana, da liberdade, da democracia, da igualdade, do Estado de direito e do respeito pelos direitos do Homem, incluindo os direitos das pessoas pertencentes a minorias. Estes valores são comuns aos Estados-Membros, numa sociedade caracterizada pelo pluralismo, a não discriminação, a tolerância, a justiça, a solidariedade e a igualdade entre homens e mulheres" (União Europeia, 1992, 2. ${ }^{\circ}$ ). Ora, este artigo estabelece os valores fundadores da UE, incluindo neste a democracia, o Estado de Direito e respeito pelos

19. Com o fim da Primeira Guerra Mundial, os húngaros viram-se confrontados com o Tratado de Paz de Trianon. Com este, o seu território foi reduzido para um terço e a sua população para dois terços. De entre outras regiões, a Hungria perdeu a Transilvânia, considerada pelos húngaros como o berço intelectual da nação. Os efeitos deste Tratado ainda hoje em dia se fazem sentir (Crampton, 1997, pp. 84-85).

20. Relatório do então eurodeputado português Rui Tavares, daí que tenha adotado o nome deste.

21. No ano de 1993, o Conselho Europeu de Copenhaga, definiu critérios de adesão, afirmando que um país associado só pode aderir à UE como Estado-Membro quando satisfizer as condições exigidas pelos critérios de Copenhaga. Estes critérios estão divididos em políticos, económicos e jurídico-administrativos. Estes critérios de adesão à União Europeia são regulados pelo artigo 49. ${ }^{\circ}$ do Tratado da União Europeia (Bugaric, 2014, p. 29). 
direitos humanos. A resolução do PE afirma que os valores patentes no $2 .^{\circ}$ artigo do TUE, juntamente com a Convenção Europeia dos Direitos Humanos e da Carta dos Direitos Fundamentais da União Europeia, exigem uma separação de poderes entre instituições independentes (Hedling, 2014, pp. 144-145).

Se o $2 .^{\circ}$ artigo do TUE estabelece os valores fundamentais da União, o 7. ${ }^{\circ}$ artigo prevê os recursos legais para punir a violação deste. Quando existe um "risco manifesto de violação grave dos valores referidos no artigo 2.o por parte de um Estado-Membro" (União Europeia, 1992, 7.'[1]), o Conselho Europeu deve ouvir o Estado-Membro em questão e dirigir-lhe recomendações adequadas para o seu caso. Este é o chamado mecanismo de prevenção descrito no artigo 7. ${ }^{\circ}$ (1) do TEU. O mecanismo de sanção, patente no artigo 7. ${ }^{\circ}(2)$ do TEU, que pressupõe a utilização de sanções - que abrangem a suspensão de certos direitos ao Estado-Membro em questão, incluindo os direitos de voto no Conselho - é desencadeado pela existência de uma violação grave e persistente do artigo 2. ${ }^{\circ}$ do TUE, por um Estado-Membro (Bugaric, 2014, pp. 4-5, 2016). Assim, a lei constitucional da UE contém disposições legais para lidar com a situação húngara. Porém, estas disposições são insuficientes para criar um conjunto de ferramentas com as quais se possa intervir, de forma eficaz, nos assuntos internos dos Estados-Membros. Uma abordagem demasiado "punitiva”, como a que é muitas vezes defendida por alguns deputados do PE, pode até piorar a situação, inibindo o processo de construção da democracia na Hungria (Bugaric, 2014, p. 3). Embora uma possível de utilização do artigo $7 .^{\circ}$ do TEU tenha sido ponderada pelo PE, o Partido Popular Europeu, uma coligação de centro-direita de diferentes partidos europeus que detém maioria no Parlamento, manifestou a sua relutância em tomar medidas sobre este assunto. Em vez disso, a Comissão Europeia decidiu dar início a diversas ações judiciais contra a Hungria (Bugaric, 2014, p. 4).

Por meio de sua resolução, o PE pronunciou-se e exerceu pressão sobre o governo húngaro para que este reconsiderasse os efeitos das suas modificações constitucionais. O PE mostrou, com as suas ações face ao caso húngaro, estar alerta em relação às questões que são para a UE de suma importância, como os valores da democracia e do Estado de Direito. No entanto, muitas das críticas apontadas à Lei Fundamental da Hungria, incluindo muitos dos aspetos identificados na resolução, não foram corrigidos pelo governo húngaro. Este tem referido que as mudanças constitucionais que têm sido feitas estão conforme a Lei húngara. O governo húngaro refere, ainda, que as alterações constitucionais são comparáveis às encontradas noutras democracias ditas consolidadas (Hedling, 2014, p. 144). Como consequência, o facto de as mudanças constitucionais húngaras violarem certos valores fundamentais e básicos da UE abre uma série de questões constitucionais e políticas importantes relacionadas com as perspetivas futuras de uma Constituição política europeia (Bugaric, 2014, p. 6, 2016).

\section{Conclusão}

A queda do Muro de Berlim e o colapso dos regimes comunistas fez com que a maioria dos países da Europa Central e de Leste tivesse iniciado a sua transição para a democracia. Entre esses países, estava a Hungria. Contudo, a transição democrática 
deste país parece ter sofrido um retrocesso nos últimos anos, estando o Estado de Direito a ser posto em causa (Dettke, 2014, p. 4). Desde o ano de 2010, com a ascensão ao poder da coligação Fidesz-KDNP, foi iniciada uma série de mudanças constitucionais, incluindo a criação da Lei Fundamental, no ano de 2011. Estas têm sido alvo de uma enorme crítica, não só pelos partidos de oposição húngaros, mas também por atores internacionais, nomeadamente pela UE (Jakab \& Sonnevend, 2013, p. 102; Tartakoff, 2012, p. 360).

O principal objetivo do presente artigo era compreender a forma como a alteração do quadro constitucional húngaro, levada a cabo pela coligação governativa Fidesz-KDNP, tem ajudado a desconstruir o Estado de Direito na Hungria. Tendo em consideração as mudanças constitucionais, e analisando-as à luz daqueles que são os traços gerais do conceito de Estado de Direito - a separação de poderes, a constitucionalidade das leis, a legalidade da administração e a independência do poder judicial, bem como a dignidade da pessoa humana, a liberdade, a justiça e a segurança - é possível argumentar que o Estado de Direito na Hungria está a ser posto em causa. As inúmeras alterações constitucionais iniciadas pelo governo de Orbán representam a deriva "autoritária" que se tem sentido no país e corroboram a ideia de que este está cada vez mais afastado dos princípios do Estado de Direito.

Dado que vivemos num mundo onde as organizações internacionais são uma realidade de organização política que está a suplantar o velho modelo do Estado soberano, afigura-se interessante ver quais serão as mudanças que a Hungria vai adotar para conseguir "sobreviver" num mundo cada vez mais globalizado. Ora, o governo de Viktor Orbán até pode estar disposto a alterar ou modificar certas leis devido à pressão internacional, mas é ponto assente que o Fidesz já deixou a sua marca na sociedade húngara e que a sua influência nesta se vai perpetuar por algum tempo. A Lei Fundamental não teve como objetivo único acabar definitivamente com o "fantasma comunista", esta foi também uma forma do Fidesz assegurar o seu futuro, a sua continuidade e o seu peso na cena política húngara. Assim se percebe que para uma série de posições centrais em órgãos determinantes da política húngara Viktor Orbán tenha nomeado pessoas leais ao partido. Deste modo, caso não tivesse ganho nas eleições de 2014 e caso não vença as de 2018, o Fidesz continuará a ser um player determinante na vida política húngara, visto que todo o aparelho estatal está impregnado de figuras da sua confiança. A Hungria deve servir como um exemplo que confirma a ideia que as democracias não dependem somente das instituições que as constituem, mas também da forma como o sistema é usado/manipulado (NHC, 2012, pp. 12-13).

O presente artigo afigura-se como mais um contributo para o estudo do conceito de Estado de Direito, focando um caso que tem gerado grande controvérsia no plano internacional, mas ao qual a academia portuguesa tem dado pouco destaque. Todavia, se neste estudo foi discutida a forma como Viktor Orbán tem desconstruído a democracia e o Estado de Direito no país, foi também referido que este modelo tem sido exportado e tem ganho espaço noutros países da região, principalmente na Polónia. Neste sentido, é sobre este país e sobre comparações deste com a Hungria 
que novas investigações se podem debruçar, de forma a que seja possível ter uma análise mais profunda e de conjunto deste fenómeno.

\section{Referências}

Amaral, M. L. (2005). A forma da República - Uma introdução ao estudo do Direito Constitucional. Coimbra: Coimbra Editora.

Bánkuti, M., Halmai, G. \& Scheppele, K. L. (2015). Hungary's illiberal turn: Disabling the Constitution. In P. Kraszter \& J. V. Til (Eds.), The Hungarian patient. Social opposition to an illiberal Democracy (pp. 37-46). Budapest: Central European University Press.

Beissinger, M, R. \& Sasse, G. (2014). An end to "patience"?. In N. Bermeo \& L. M. Bartels (Eds.), Mass politics in tough times: Opinions, votes, and protest in the Great Recession (pp. 334-370). Oxford: Oxford University Press.

Bobbio, N. (1987). The future of Democracy. Minneapolis: University of Minnesota Press.

Bugaric, B. (2014). Protecting Democracy and the Rule of Law in the European Union: The hungarian challenge. (LEQS Paper no. 79). London, UK: London School of Economics and Political Science. <http://www.lse.ac.uk/europeanInstitute/LEQS/LEQSPaper79.pdf> (acedido em janeiro de 2017).

Bugaric, B. (2016). Protecting Democracy inside the EU: On article 7 TEU and the hungarian turn to Authoritarianism. In C. Closa \& D. Kochenov (Eds.), Reinforcing Rule of Law oversight in the European Union (pp. 82-101). Cambridge: Cambridge University Press.

Canotilho, G. (1999). Estado de Direito. Lisboa: Gradiva.

Cartledge, B. (2011). The will to survive - A History of Hungary. London: Hurst \& Company.

Crampton, R. J. (1997). Eastern Europe in the twentieth century - and after. London: Routledge.

Dettke, D. (2014). Hungary's Jobbik Party, the challenge of European Ethno-Nationalism and the future of the European Project. (Reports and Analysis no. 4). Warsaw: Center for International Relations. <http://csm.org.pl/en/2014/669-partia-jobbik-na-wegrzech-wyzwanie-europejskiego-etnonacjonalizmu-i-przyszlosc-projektu-europejskiego-2> (acedido em fevereiro de 2017).

Grabenwarter, C., Hoffmann-Riem, W., Suchocka, H., Tuori, K. \& Velaers, J. (2013). Opinion on the Fourth Amendment to the Fundamental Law of Hungary. Strasbourg: European Commission for Democracy Through Law (Venice Commission). <http://www.venice. coe.int/webforms/documents/default.aspx?pdffile=CDL-AD(2013)012-e> (acedido em março de 2017).

Hedling, N. (2014). Developing mechanisms for regional influence in national processes of constitutional change: The European Union and Hungary. In R. Cordenillo \& K. Sample (Eds.), Rule of Law and constitution building: The role of regional organizations (pp. 141-159). Stockholm: International IDEA.

Jakab, A., \& Sonnevend, P. (2013). Continuity with deficiencies: The new basic law of Hungary. European Constitutional Law Review, 9(1), 102-138.

Kovács, K., \& Tóth, G. A. (2011). Hungary’s constitutional transformation. European Constitutional Law Review, 7(2), 183-203.

Lendvai, P. (2012). Hungary: between Democracy and Authoritarianism. London: C. Hurst \& Co. 
Lewis, P., Lomax, B., \& Wightman, G. (1994). The emergence of multi-party systems in East-Central Europe. A comparative analysis. In G. Pridham \& T. Vanhanem (Eds.), Democratization in Eastern Europe: domestic and international perspectives (pp. 151188). London: Routledge.

Ministry of Justice of Hungary. (2011). The Fundamental Law of Hungary. Hungary: Ministry of Justice of Hungary. <http://www.parlament.hu/documents/125505/138409/Fundamental+law/73811993-c377-428d-9808-ee03d6fb8178> (acedido em abril de 2017).

Miranda, J. (2011). Manual de Direito Constitucional, Tomo I. Coimbra: Coimbra Editora.

Muller, J. W. (2011). The Hungarian tragedy. Dissent, 58(2), 5-10.

Nagy, A. B., Boros, T., \& Vasali, Z. (2013). More radical than the Radicals: the Jobbik Party in international comparison. In R. Melzer \& S. Serafin (Eds.), Right-wing extremism in Europe - Country analyses, counter-strategies and labor-market oriented exit strategies (pp. 229-254). Berlin: Friedrich-Ebert-Stiftung Forum Berlin.

Norwegian Helsinki Committee (NHC). (2012). Democracy at stake in Hungary - The Orbán government's Constitutional revolution. Oslo: Norwegian Helsinki Committee. <http:// www.venice.coe.int/webforms/documents/default.aspx?pdffile=CDL-AD(2013)012-e> (acedido em abril de 2017).

Novais, J. R. (1987). Contributo para uma teoria do Estado de Direito: do Estado de Direito Liberal ao Estado social e democrático de Direito. Coimbra: Coimbra Editora.

Novak, B. (2014). Scheppele on democracy, constitutionalism, and Rule of Law in Hungary. The Budapest Beacon. Disponível em <http://budapestbeacon.com/public-policy/ scheppele-on-democracy-constitutionalism-and-rule-of-law-in-hungary/> (acedido em março de 2017).

Rupnik, J. (2012). How things went wrong. Journal of Democracy, 23(3), 132-137.

Sadecki, A. (2014). In a state of necessity - How has Orban changed Hungary. (Point of View no. 41). Warsaw: Centre for Eastern Studies. <https://www.osw.waw.pl/sites/default/files/ pw_41_in-a-state-of-necessity_net.pdf> (acedido em abril de 2017).

Scheppele, K. L. \& Krugman, P. (2011). Hungary's Constitutional Revolution. The New York Times - The Conscience of a Liberal. Disponível em <http://krugman.blogs.nytimes. com/2011/12/19/hungarys-constitutional-revolution/> (acedido em maio de 2017).

Stegmaier, M., \& Lewis-Beck, M. (2011). Shocks and oscillations: The political economy of Hungary. Electoral Studies, 30(3), 462-467.

Tartakoff, L. Y. (2012). Religion, Nationalism, History, and Politics in Hungary's new Constitution. Society, 49(4), 360-366.

Tavares, R. (2012). On the situation of fundamental rights: standards and practices in Hungary. European Union: Committee on Civil Liberties, Justice and Home Affairs. <http://www.europarl.europa.eu/sides/getDoc.do?pubRef=-//EP//TEXT+REPORT+A7-2013-0229+0+DOC+XML+V0//EN (acedido em março de 2017)>.

União Europeia. (1992). Tratado da União Europeia. Disponível em <http://europa.eu/eu-law/ decision-making/treaties/pdf/consolidated_versions_of_the_treaty_on_european_ union_2012/consolidated_versions_of_the_treaty_on_european_union_2012_ pt.pdf> (acedido em abril de 2017). 


\section{Sobre a autora}

MARIANa CARmo DUARTe é licenciada em Ciência Política e Relações Internacionais, pela FCSH/NOVA, e mestre em Ciência Política, pelo ISCTE-IUL. Atualmente, é bolseira de investigação no CIES-IUL. Os seus principais interesses de investigação são atitudes e comportamentos políticos; sistemas eleitorais; política da Europa de Leste; autoritarismo, democracia, imigração e nacionalismo.

\section{About the author}

MARIANA CARMO DUARTE holds a bachelor's degree in Political Science and International Relations from FCSH/NOVA and a master's in Political Science from ISCTE-IUL. Currently, she is a research fellowship at CIES-IUL. Her main research interests are political behavior, electoral systems, Eastern European policy, authoritarianism, democracy, immigration and nationalism. 